\title{
Five-year experience in transradial approach for coronary procedures at Zadar General Hospital
}

\author{
Dražen Zekanović*, Jogen Patrk, Ante Anić, Zorislav Šušak, Zoran Bakotić, Albino Jović, \\ Davor Nekić \\ Zadar General Hospital, Zadar, Croatia
}

\begin{abstract}
Background: Since its introduction in 1989, transradial approach (TRA) for coronary diagnostic and interventional procedures has seen continuous advancement. The reasons for widely adoption of this approach are accessible and superficially placed radial artey which is easily compressed, thus minimizing heamorrhagic and other local complications, enabling early patient ambulation and hospital cost decrease. All of this has been confirmed in large randomized controlled trials.
\end{abstract}

Methods: Retrospective, single center analysis of all consecutive TRA procedures performed in Zadar General Hospital Cath Lab between January 2008 and December 2012.

Results: Out of 1877 TRA procedures, $739(37 \%)$ were $\mathrm{PCl}$ cases. Transition to TRA to allcomers was fast for diagnostic procedures, during 2009, and more gradual for interventional procedures including primary $\mathrm{PCl}(\mathrm{pPCl})$, in 2010 and 2011. As a result, in 2012 we performed $133 \mathrm{pPCl}$ via TRA which represents $90 \%$ of whole $\mathrm{pPCl}$ volume. No single complication happened that needed surgical intervention.
Conclusion: Since our first transradial coronary angiography in fall 2007 and as a first TRA dedicated center in Croatia, our numbers and experience point toward fact that TRA is easy to adopt, safe to perform and results in better patient satisfaction and not least, cuts hospital costs through earlier patient ambulantion and exceptionally low rate of complications needing surgical intervention.

KEYWORDS: coronary artery disease, transradial approach, percutaneous coronary intervention.

Received: $27^{\text {th }}$ Feb 2013
*Address for correspondence: Opća bolnica Zadar, B. Peričića 5, HR-23000 Zadar,
Croatia.
Phone: +385-23-505-505
E-mail: dzekanovic@ bolnica-zadar.hr

\section{Literature}

1. Lukenda J. [Transradial approach in interventional cardiology: "quod licet femoralisti, non licet radialisti"]. Lijec Vjesn 2012;134:178-85.

2. Bertrand OF, Rao SV, Pancholy S, et al. Transradial approach for coronary angiography and interventions: results of the first international transradial practice survey. JACC Cardiovasc Interv. 2010;10:1022-31.

3. Jolly SS, Yusuf S, Cairns J, et al, for the RIVAL trial group. Radial versus femoral access for coronary angiography and intervention in patients with acute coronary syndromes (RIVAL): a randomised, parallel group, multicentre trial. Lancet. 2011;377:1409-20. 